\title{
PEMODELAN REWARD RULE GAME STREAMER INDONESIA TINGKAT AMATIR DENGAN ORANGE DATA MINING
}

\author{
Erlin Windia Ambarsari ${ }^{1}$, Siti Khotijah ${ }^{2}$, Lies Sunarmintyastuti ${ }^{3}$ \\ Informatika, Universitas Indraprasta PGRI ${ }^{1,2,3}$ \\ erlin.windia@unindra.ac.id ${ }^{1}$
}

Submitted April 14, 2019; Revised June 19, 2019; Accepted June 29, 2019

\begin{abstract}
Abstrak
Bukan menjadi suatu hambatan bagi pemain Game untuk dapat bermain. Namun, mereka dapat pula mendapatkan komisi sebagai penghasilan mereka dengan cara melakukan siaran langsung saat mereka sedang bermain. Platform yang menyediakan Live Streaming Game yang tidak hanya menguntungkan pemain, melainkan juga Industri Game. Namun berdasarkan pengamatan penulis, poin yang didapatkan tidak sesuai dengan aturan komisi (Reward Rule), padahal pencapaian target sudah terpenuhi. Hal ini membuat keresahan para pemain yaitu Game Streamer yang menjadikan Game sebagai penghasilan utama. Oleh karena itu, perlu dilakukan pemetaan data Live Streaming, dengan cara membuat suatu pemodelan untuk mengklasifikasi data yang didapatkan dari sebuah agensi Cube TV berdasarkan analisis deskriptif. Pemodelan dilakukan dengan mengunakan metode Decision Tree dari Orange Data Mining. Hasil yang ditemukan dari studi kasus ini adalah terdapat poin Rate yang menjadi penentuan komisi belum ditemukan korelasi variabelnya. Sehingga perlu ada kriteria yang spesifik untuk mendapatkan bobot-bobot ideal yang harus dicapai oleh para pemain.
\end{abstract}

Kata Kunci : Live Streaming Game, Reward Rule, Decision Tree, Orange Data Mining

\begin{abstract}
There is no more obstacle hampering Game players from playing games. Today, they can even get a reward as their income by doing live broadcasts while playing a game. The platform that provides Live Streaming Games does not only benefit players, but also the Game Industry. Yet, based on the researchers' observation, the points obtained are not in accordance with the reward rule, even though the target has been achieved. This condition unsettles Game Streamers who make Game their main income. Therefore, it is necessary to map Live Streaming data by creating a model to classify the data obtained from a Cube TV agency based on descriptive analysis. The modeling is conducted using the Decision Tree method from Orange Data Mining. The result of the case study shows that variable correlation of Rate point used to determine the reward has not been found. So, it necessary to establish specific criteria to get the ideal qualities that must be achieved by the players.
\end{abstract}

Keywords: Live Streaming Game, Reward Rule, Decision Tree, Orange Data Mining

\section{PENDAHULUAN}

Seperti yang dilansirkan pada penelitian sebelumnya[1] mengenai pemasaran Gim (Game) tergantung dari nilai produk yang dijual berdasarkan kebutuhan Gamer masa sekarang. Produk-produk dari Industri Game tersebut dapat dipasarkan ke dalam platfrom distribusi digital seperti Steam, Emago, Playstore ataupun App Store.

Namun berdasarkan pengamatan penulis, kebiasaan para Gamer cenderung tidak hanya bermain sebagai single player maupun multiplayer, mereka juga berbagi permainan mereka kepada non-player sehingga tidak hanya Gamer yang menikmati jalannya sebuah permainan, akan tetapi penontonpun dapat mengikuti alurnya.

Karena itu, para Gamer memanfaatkan media sebagai penyampaian informasi dalam bentuk visual yang dilakukan melalui video untuk disimpan dan dibagi secara daring, misalkan media yang 
digunakan adalah Youtube sebagai situs web berbagi video.

Youtube mengembangkan fitur Live Streaming yaitu YouTube Live, dengan tujuan Youtuber dapat berinteraksi langsung dengan penonton dan menambahkan fitur chat agar penonton dapat berkomunikasi dengan Youtuber.

Hal ini yang mendorong para startup untuk membuat strategi dalam mengembangkan pemasaran produk Game dengan memanfaatkan Live Streaming sebagai bisnis baru yang melibatkan tiga pihak, yaitu Pengembang, Pemain dan Penonton.

Pemain yang menjalankan produk para pengembang Game, yang kemudian disiarkan langsung. Penonton dapat berkomunikasi dengan pemain yang pada saat itu juga akan memberikan komentar.

Keuntungan yang didapatkan dari pemasaran ini adalah dapat mendongkrak jumlah pemain yang memainkan Game, dikarenakan jika ada produk Game yang menarik penonton, kemungkinan mereka akan memainkan Game yang sama. Ini akan menguntungkan Industri Game dalam mengembangkan dan memasarkan produk. Apalagi jika diadakan kompetisi Game Online yang dilakukan oleh industri $e$ sport dengan dimainkan oleh pemain profesional[2], akan dapat menguntungkan pihak sponsor dengan biaya murah jika memanfaatkan platform yang dibuat oleh startup.

Salah satu startup yang popular di Indonesia adalah Cube TV, sebuah platform khusus Live Streaming Game yang melibatkan tiga pihak yang disebutkan sebelumnya. Cube TV tidak hanya menyediakan pemain Game disebut sebagai Game Streamer untuk menyiarkan jalannya permainan saja. Mereka juga diberikan komisi atau reward setiap melakukan penyiaran dengan syarat yang sudah ditentukan. Pembagian komisi pemain dibagi dalam beberapa tingkatan, yaitu S, A, dan B sesuai dengan aturan masing-masing negara yang meliputi Brazil, Filipina, Taiwan, Rusia, Indonesia, Malaysia, Vietnam dan India.

Di Indonesia sendiri, tingkatan yang diakui adalah tingkat A (A1 dan A2) dan B (B1 dan B2), sedangkan untuk diluar tingkatan itu disebut Game Streamer Pemula atau Amatir yang tingkatannya yaitu $\mathrm{C}(\mathrm{C} 1, \mathrm{C} 2$, C3, C4) dan other (tidak punya tingkat). Poin yang didapatkan pada tingkatan kecil yaitu C4 adalah 10.500 atau komisi ratarata $\$ 50$. Hal inilah yang mendorong Game Streamer untuk mengejar target agar mendapatkan penghasilan melalui Game.

Namun berdasarkan pengamatan penulis, poin yang didapatkan tidak sesuai dengan aturan komisi (Reward Rule) yang sudah ditentukan dan bahkan tidak mendapatkan komisi sama sekali, padahal pencapaian target sudah terpenuhi. Hal ini membuat keresahan para Game Streamer yang menjadikan Game sebagai penghasilan utama.

Oleh karena itu, untuk memecahkan masalah tersebut, penulis akan memetakan data dari pencapaian target Game Streamer beserta komisi untuk mendapatkan Reward Rule sebenarnya.

Pemetaan data dilakukan dengan cara membuat pemodelan yang kemudian dianalisa sehingga diketahui apakah ada syarat yang belum dijelaskan dan bagaimana rincian syaratnya. Pemodelan tersebut dilakukan dengan menggunakan tools dari Orange Data Mining[3].

Penelitian dengan memanfaatkan Orange Data Mining dalam berbagai pemodelan data, dilakukan oleh peneliti-peneliti lain seperti pada [4] dengan melakukan beberapa pengujian model dari classification tree dan random forest untuk memprediksi prakiraan tinggi gelombang laut, dimana tingkat keakuratan classification tree lebih besar $88 \%$ dibandingkan dengan random forest; lain 
halnya dengan [5] yang penerapannya menggunakan decision tree dengan proses regresi linier dalam klasifikasinya kepada pengambilan keputusan dalam memproritaskan bantuan Bahan Bakar Gas (BBG) kepada masyarakat daerah Kabupaten Cilacap; sedangkan dari penelitian [6] membahas mengenai analisis jaringan dimana dalam pemodelannya memanfaatkan komponen Orange Data Mining. Pada penelitian yang disebutkan sebelumnya, Orange Data Mining membantu menganalisis karakteristik data atau dengan kata lain dapat digunakan untuk pengenalan pola dengan metode clustering, classification, regression, neural network, dan lain sebagainya.

Oleh karena itu, penulis menggunakan metode classification yang penarikan datanya mirip pada penelitian [7] dimana data-datanya diambil dari data statistik pengunjung yang tertanam pada situs web dengan menggunakan Google Analytics.

Pada penelitian ini menggunakan data statistik streaming yang dibangun oleh pihak Cube TV dalam sistem platform mereka. Data statistik tersebut kemudian dianalisis dengan menggunakan decision tree dalam menyelesaikan studi kasus yang dimodelkan dalam Orange Data Mining.

Tujuan dari penelitian ini adalah mencari aturan komisi sebenarnya yang tidak dijelaskan dari pihak Cube TV dengan mengamati pola data pencapaian kinerja Game Streamer yang terekam pada sistem platform Live Streaming milik perusahaan tersebut, sehingga diperlukan perbaikan manajemen operasional untuk kedepannya yang menguntungkan kedua pihak yaitu Pengembang Cube TV dan Game Streamer.

\section{METODE PENELITIAN}

Pada studi kasus ini, penelitian menggunakan metode analisis deskriptif untuk mencari hubungan dari beberapa variabel dimana hasil yang didapatkan berupa association rule, yang merupakan induksi aturan dengan mengidentifikasi ifthen secara terurut sebagai pencarian heuristik [8]. langkah-langkah yang akan diambil untuk identifikasi aturan komisi adalah sebagai berikut:

\section{A. Pengumpulan Data}

Data yang kumpulkan adalah data statistik streaming yang dianalisis oleh sistem di dalam platform Cube TV dimana datanya ditarik dari aktivitas Game Streamer yang sedang melakukan siaran langsung (Live Streaming)

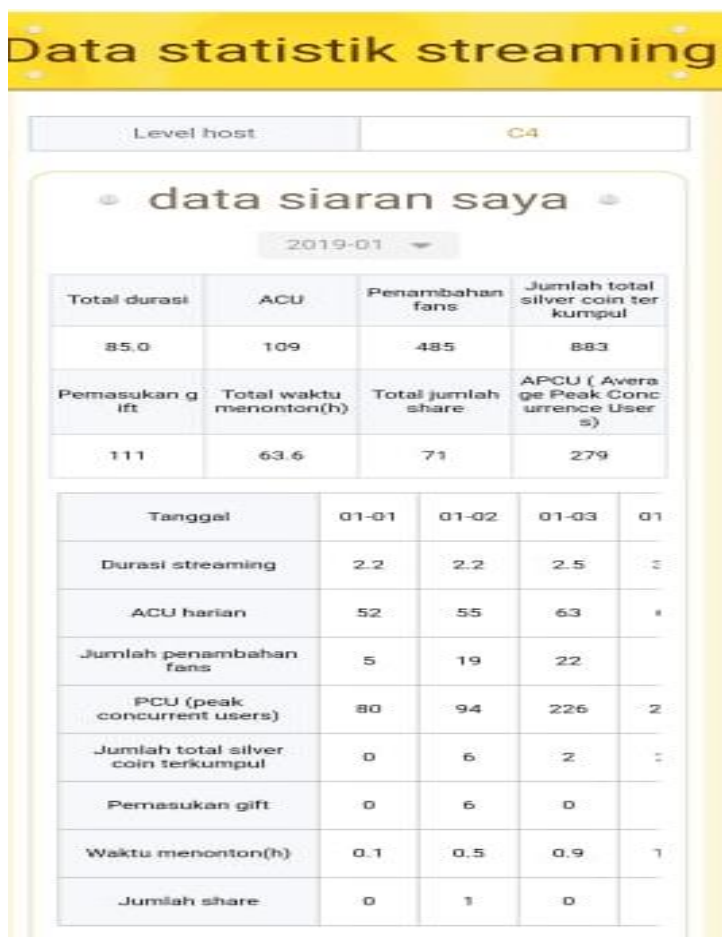

Gambar 1. Data Statistik Streaming Cube TV

Sistem didalam Cube TV kemudian dihitung untuk mendapatkan komisi perbulan yang nantinya akan diteruskan kepada agensi sebagai laporan pendapatan, sesuai dengan aturan umum yang diberikan oleh Admin platform Cube TV untuk masing-masing negara dalam komunitas Game, seperti gambar dibawah ini: 


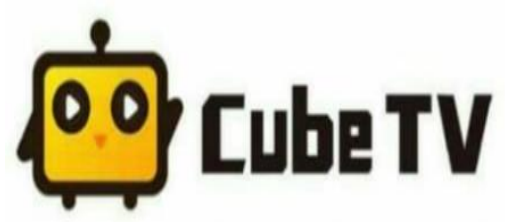

Open Recruitment host gaming by cube tv

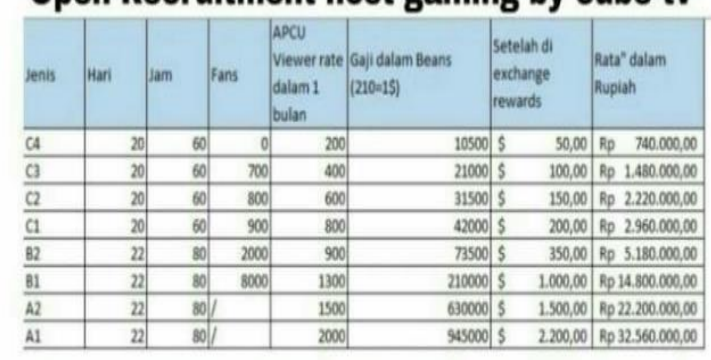

Gambar 2. Komisi Cube TV Khusus Indonesia

Berdasarkan gambar diatas, bahwa tingkat C4 mendapatkan komisi \$50 (10.500) atau rata-rata $\mathrm{Rp} 740.000$,- dengan syarat waktu selama 20 hari untuk 60 jam, APCU (Average Peak Concurrence Users) dalam 1 bulan antara 200-399 dan target energi adalah 390; C3 dengan komisi \$100 (21.000) dengan syarat waktu selama 20 hari untuk 60 jam, fans 700 orang, APCU antara 400-599, dan target energi 540; C2 dengan komisi $\$ 150$ (31.500), waktu 20 hari untuk 60 jam, fans 800 orang, APCU 600-799, dan target energi 790; C1 dengan komisi \$200 (42.000), waktu 20 hari untuk 60 jam, fans 900 orang, APCU 800-899, dan target energi 720; B2 dengan komisi \$350 (73.500), waktu 20 hari untuk 80 jam, fans 2000 orang, APCU 900-1299, dan target energi 1050; B1 dengan komisi $\$ 1000$ (210.000), waktu 22 hari untuk 80 jam, fans 8000, APCU 1300-1499, dan target energi 1770; A2 dengan komisi $\$ 1500$ (630.000), waktu 22 hari untuk 80 jam, fans >8000, APCU 1500-1999, target energi 1970; A1 dengan komisi $\$ 2200$ (945.000), waktu 22 hari untuk 80 jam, fans >8000, APCU>2000, target energi 2500 .

Namun, laporan pendapatan yang didapatkan penulis dari satu agensi dengan sebanyak 114 data Game Streamer pada bulan Januari 2019 mempunyai sedikit perbedaan dengan beberapa kondisi, seperti terdapatnya APCU Awal, Rate, APCU Akhir, Followers, Jam Siaran (Detik), Hari Siaran, Energy, Level Host, Pelanggaran, Reissue, untuk mendapatkan kelayakan Komisi. Selain itu, tingkatan yang didapatkan pada laporan tersebut adalah C2, C3, C4 dan other (tingkatan tidak tertulis pada aturan umum). Oleh karena itu, diperlukan klasifikasi kembali bagaimana aturan yang sudah ditentukan sebelumnya.

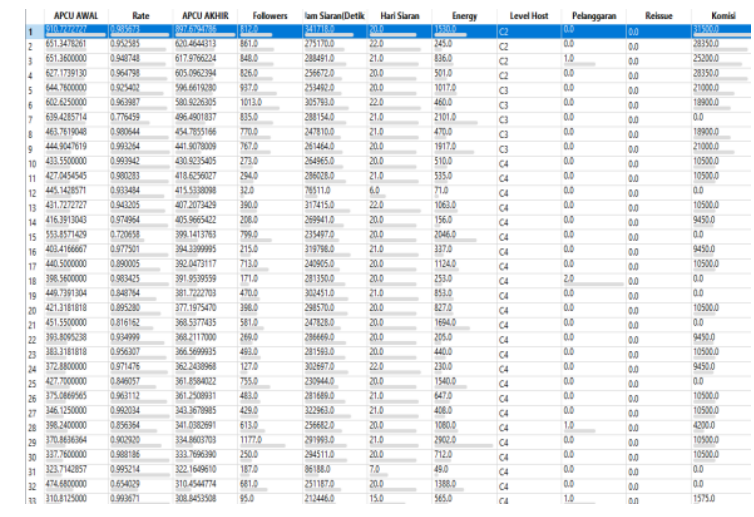

Gambar 3. Sampel Data Laporan Komisi Game Streamer

\section{B. Decision Tree}

Decision Tree (Pohon Keputusan) merupakan metode classification (klasifikasi) yang dapat digunakan dalam statistik, machine learning, pengenalan pola, maupun Data Mining. Metode ini berdasarkan dari struktur pohon yang dibuat bercabang, berawal dari simpul (node) root dan diakhiri dengan simpul daun (leaf)[9].

Decision Tree mempunyai beberapa versi yaitu ID3[10], C4.5[11], J48 (versi weka)[12], C5.0[13]. Namun, pada Orange Data Mining menggunakan ID3 yang bukan hanya berperan sebagai klasifikasi, tetapi juga dapat melakukan regresi, seperti halnya pada metode CART[14]. Klasifikasi itu sendiri dimaksud adalah dataset yang mempunyai sifat kategorik untuk menemukan model yang menjelaskan kelompok atau class dari attribute yang 
terdapat pola. Dengan kata lain, dataset akan dibagi berdasarkan kelompoknya. Namun untuk regresi tidak dijabarkan menjadi suatu kelompok untuk pencarian pola karena datasetnya bersifat numerik atau kontinu. Oleh karena itu, khusus regresi dalam pembagian datanya menggunakan scatter plot[15] yang kemudian dihitung rate errornya, dimana yang dipilih berdasarkan nilai minimum. Pembagian dataset inilah sebagai dasar pembangunan struktur pohon dalam decision tree.

Kemudian, dalam pembangunan pohon kadangkala terjadi kompleksitas atau overfitting yaitu ada beberapa node yang merupakan hasil dari noise data ataupun outliner[16]. Oleh karena itu, diperlukan pemangkasan pohon untuk menguranginya agar meningkatkan akurasi prediksi cabang pohon yang akan dibangun. Pemangkasan pohon disebut sebagai Pruning; yang terdiri dari Pre-Pruning dan Post-Pruning.

Pre-Pruning atau disebut juga Forward Pruning digunakan untuk mencegah generasi cabang yang tidak signifikan, melibatkan penggunaan kondisi pemutusan untuk mengakhiri beberapa cabang sebelum pembentukan[17].

Post-Pruning yang dikenal sebagai Backward Pruning, dimana hasil pohon keputusan yang dibentuk dan ternyata tidak signifikan, maka perlu dihapus. PostPruning dimulai dengan menghasilkan pohon yang lengkap dan kemudian disesuikan dengan meningkatkan akurasi klasifikasi yang tidak terlihat. Terdapat dua metode pendekatan untuk melakukan pruning ini, yaitu metode dengan mengubah pohon menjadi persamaan kumpulan aturan, dan metode dengan mempertahankan decision tree dimana mengganti beberapa sub-pohon dengan simpul daun. Sehingga mengubah pohon yang lengkap kedalam pemangkasan yang lebih kecil untuk memprediksi klasifikasi yang tidak terlihat[17].
Pada pemodelan aturan komisi ini, untuk pemangkasannya didalam decision tree menggunakan Forward Pruning[18], yaitu dengan membagi data menjadi simpul (node) berdasarkan kelas purity. Pohon ini dirancang untuk menangani dataset terpisah dan kontinu. Karena itu, pohon pada Orange Data Mining dapat pula digunakan untuk klasifikasi.

Pembangunan pohon tersebut diatur dalam parameter Tree dan dapat dilihat pada Gambar 4.

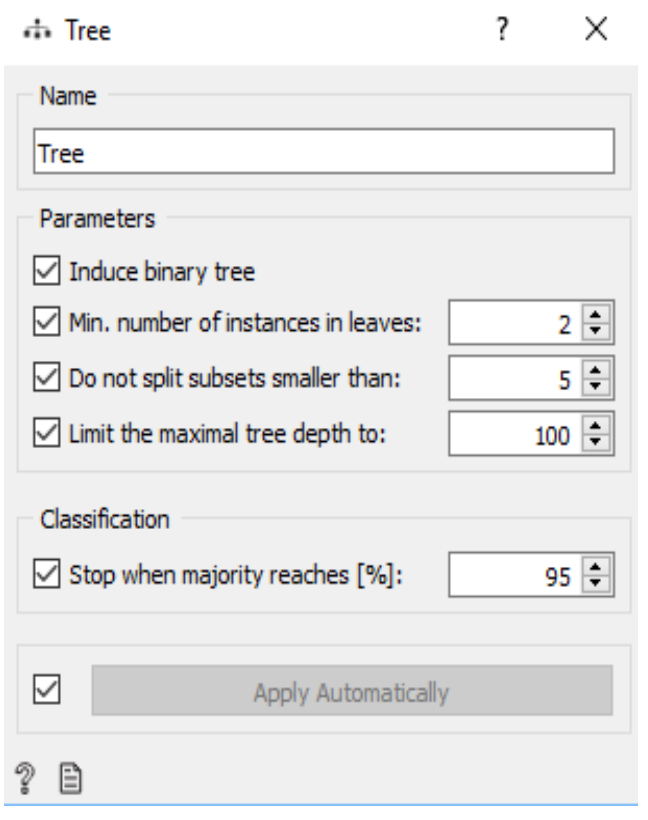

Gambar 4. Parameter Tree (pohon)[3]

Parameter Tree (pohon) sebagai berikut:

1) Induce binary tree: membangun pohon binary (dibagi kedalam dua child node)

2) Min. number of instances in leaves: jika dicentang, algoritma tidak akan pernah membangun pemisahan yang akan menempatkan kurang dari jumlah contoh pelatihan yang ditentukan ke dalam salah satu cabang.

3) Do not split subsets smaller than: algoritma tidak diperkenankan untuk membagi node lebih sedikit dari jumlah instance yang diberikan.

4) Limit the maximal tree depth: membatasi kedalaman pohon yang 
diklasifikasi ke jumlah tingkat node yang ditentukan.

5) Stop when majority reaches [\%]: Menghentikan pemisahan node setelah ambang batas (threshold) yang sudah ditentukan sudah tercapai.

\section{HASIL DAN PEMBAHASAN}

Berdasarkan pemaparan pada metode penelitian, maka langkah-langkah yang perlu diperhatikan didalam pemodelan Reward Rule adalah sebagai berikut:

1) Menyaring data yang diperlukan untuk digunakan dalam menganalisa Reward Rule.

2) Memasukan data yang sudah diseleksi ke dalam Tree.

3) Membuat Decision Tree yang kemudian dianalisa aturan komisi para Game Streamer berdasarkan association rule.

Sehingga pemodelan yang dibuat berdasarkan langkah-langkah diatas, dapat dilihat pada gambar dibawah ini:

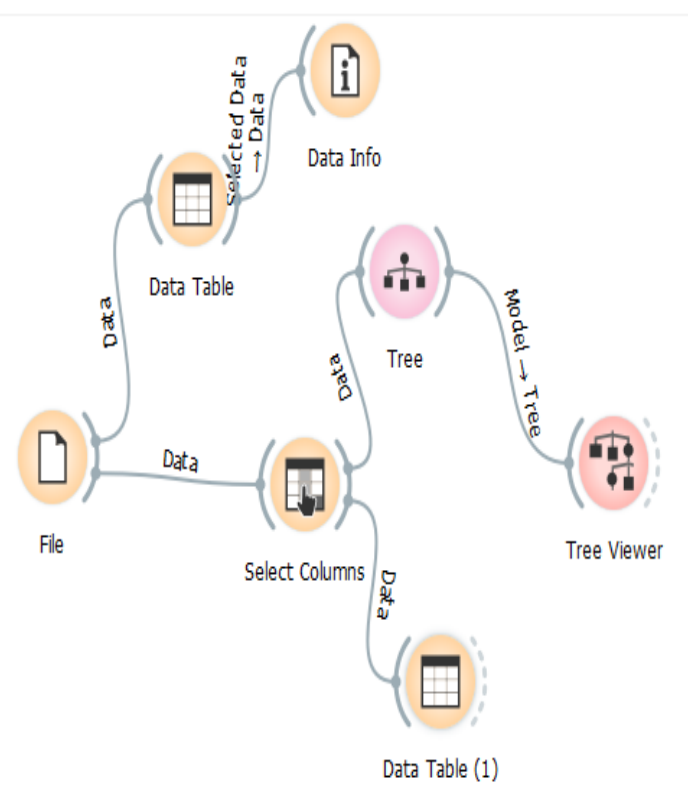

Gambar 5. Pemodelan Reward Rule

File yang didapatkan dari laporan pendapatan terdiri dari beberapa feature, yaitu ID HOST, No, ID AGENCY, APCU
Awal, Rate, APCU Akhir, Followers, Jam Siaran (Detik), Hari Siaran, Energy, Level Host, Pelanggaran, Reissue, dan Komisi.

Beberapa feature tersebut kemudian disaring pada Select Columns dan diatur seperti gambar 6, dimana terdapat 9 feature yang digunakan sebagai atribut (APCU Awal, Rate, APCU Akhir, Followers, Jam Siaran (Detik), Hari Siaran, Energy, Level Host, Pelanggaran), 1 target variable yang digunakan sebagai class (Komisi), dan meta attributes atau disebut dengan instance dari 114 data ID HOST.

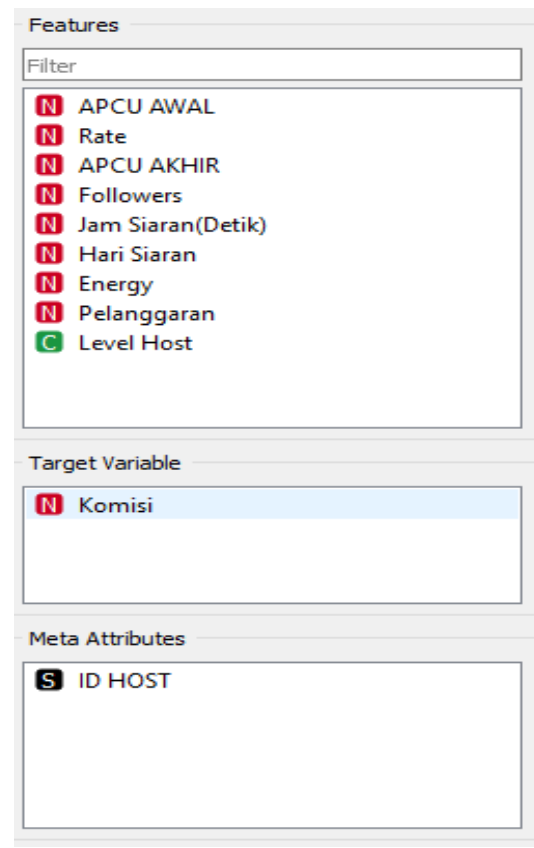

Gambar 6. Select Columns[3]

Berdasarkan pada Gambar 6 diatas, bahwa ada beberapa attribute yang mempunyai kumpulan data yang bersifat numerik yaitu APCU Awal, Rate, APCU Akhir, Follower, Jam Siaran (Detik), Hari Siaran, Energy, Pelanggaran, serta class Komisi. Sedangkan kumpulan data yang bersifat kategorik terdapat pada attribute Level Host. Hal ini berarti tidak dapat diklasifikasi dengan cara pengelompokkan data, sehingga dalam membangun sebuah pohon dapat menggunakan regresi atau disebut dengan Regression Tree. Oleh karena itu, perlu dilakukan pengkajian lebih lanjut dalam penelitian untuk proses 
perhitungan dari Regression Tree pada studi kasus ini.

Kemudian, data yang sudah diseleksi pada Gambar 6, dibuat dalam pemodelan Tree pada Data Mining Orange untuk membangun Decision Tree yang diperlihatkan pada Tree Viewer dalam Gambar 7, sehingga hasil pelatihannya dapat dilihat pada gambar berikut :

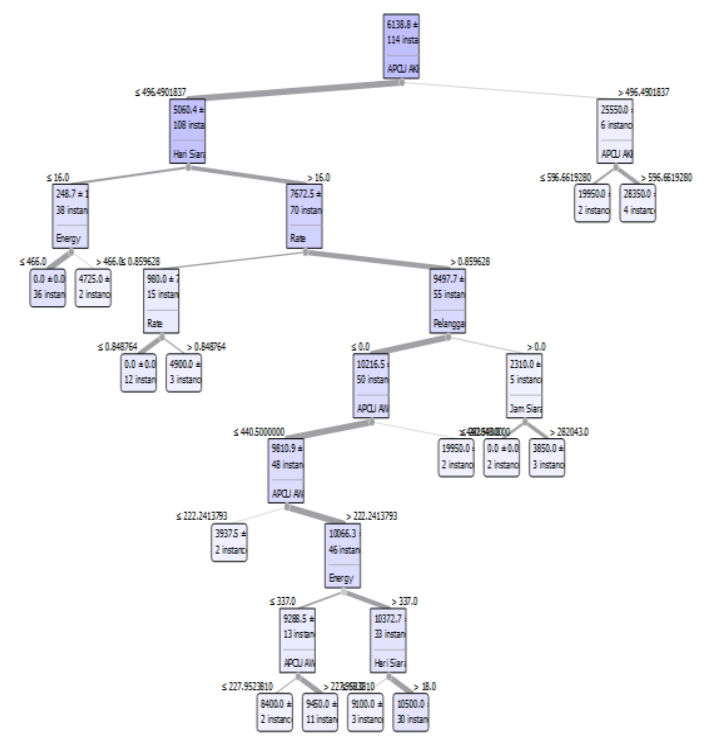

Gambar 7. Decision Tree

Berdasarkan gambar 7, data yang dapat diklasifikasi adalah data Game Streamer tingkat $\mathrm{C} 4$. Alasannya adalah baik tingkat C2 dan C3 nilai atributnya tidak spesifik (dengan kata lain sedikit sekali Game Streamer berada ditingkat atas), begitu pula untuk other yang dikarenakan tidak akan mendapatkan komisi jika belum dapat mencapai tingkat $\mathrm{C} 4$, sehingga pohon tidak dapat mengklasifikasikan kombinasi nilai atribut yang tidak terlihat dalam pelatihan, karena itulah dilakukan pemangkasan (pruning).

Oleh karena itu, Rule Reward yang didapatkan dari Decision Tree pada tingkat C4 sebanyak 46 instance yang dapat diklasifikasi adalah sebagai berikut:

1) Komisi 10.500 dengan 30 instance; Hari Siaran > 18, Energy > 337, $222,2413793<$ APCU $\quad$ Awal $<=440,5$,
Pelanggaran $<=0$, Rate > 0,859628, APCU Akhir <= 496,4901837.

2) Komisi 9100 dengan 3 instance; $16<$ Hari Siaran <= 18, Energy > 337, $222,2413793<$ APCU $\quad$ Awal $<=440,5$, Pelanggaran $<=0$, Rate $>0,859628$, APCU Akhir $<=496,4901837$.

3) Komisi 9450 dengan 11 instance; $227,9523810<$ APCU Awal <= 440,5, Energy $<=337$, Pelanggaran $<=0$, Rate $>0,859628$, Hari Siaran >16, APCU Akhir $<=496,4901837$.

4) Komisi 8400 dengan 2 instance; $222,2413793<$ APCU Awal <= 227,953810, Energy $<=337$, Pelanggaran $<=0$, Rate $>0,859628$, Hari Siaran >16, APCU Akhir <= 496,4901837.

Berdasarkan association rule dari Decision Tree, maka syarat yang digunakan untuk pemenuhan komisi Game Steamer tingkat C4 dengan instance terbanyak, dimana Komisi yang didapatkan 10.500 atau setara dengan \$50; dengan waktu selama 20 hari untuk 60 jam (paling sedikit waktu siaran > 18 hari), APCU dalam 1 bulan antara 200399 yaitu sekitar 222,2413793<APCU Awal $<=440,5$ dan APCU Akhir <= 496,4901837, target energi adalah 390 yaitu batas minimal adalah Energy > 337, tidak ada pelanggaran, dan Rate> 0,859628 .

Berarti berdasarkan laporan pendapatan, terdapat dua poin yang belum dijelaskan pada aturan umum, antara lain mengenai pelanggaran dan Rate. Pelanggaran itu sendiri dimaksudkan jika Game Streamer menyalahi aturan yang berlaku sesuai dengan peraturan menteri KOMINFO No. 11 Tahun 2016 seperti larangan konten pornografi dan kekerasan, serta aturan tidak tertulis yang ditetapkan oleh Cube TV sendiri. Namun, penulis tidak dapat menemukan asal dari Rate, dimana korelasi data-datanya baik berasal dari data statisik streaming maupun dari laporan 
pendapatan. Padahal Rate tersebut adalah poin penting dalam penentuan komisi. Jika para Game Streamer tidak memenuhi nilai Rate, walaupun semua persyaratan sudah terpenuhi, mereka tetap tidak mendapatkan komisi. Karena itu, sangat perlu transparasi sebuah nilai Rate tersebut. Jika tidak dilakukan, maka terjadi pendugaan penyelewengan yang dilakukan oleh pihak pengembang. Kemudian, karena aktivitas Live Streaming Game masih tergolong baru di Indonesia dan perihal bisnis platform ini belum ada regulasi yang tepat dari pemerintah. Sehingga, perlu dilakukan penelitian selanjutnya untuk mengetahui fakta yang lebih dalam dengan memahami hubungan bisnis dan strategisnya dalam pembuatan keputusan terutama masalah memperoleh pendapatan dari sebuah konten. Sehingga kriteria sebagai syarat perolehan komisi dapat lebih jelas bagaimana mendapatkan bobot-bobot ideal yang harus dicapai oleh para pemain.

\section{SIMPULAN}

Pemodelan yang dibuat untuk pemetaan komisi yang didapatkan oleh Game Streamer dengan cara dilakukan klasifikasi data yang didapatkan dari satu agensi dengan 114 instance. Namun, hanya tingkat C4 yang dapat diklasifikasi dikarenakan tingkat lain dipangkas oleh Decision Tree didalam pemodelan tersebut. Alasannya adalah nilai atributnya tidak spesifik. Karena itu, diperlukan penambahan data untuk dapat mengenali pola secara keseluruhan dengan mengambil lebih dari satu agensi yang tersebar di seluruh Indonesia. Reward Rule yang didapatkan dari hasil perolehan pemodelan berdasarkan association rule yaitu komisi yang didapatkan 10.500 atau setara dengan $\$ 50$; dengan waktu selama 20 hari untuk 60 jam (paling sedikit waktu siaran > 18 hari), APCU dalam 1 bulan antara 200-399 yaitu sekitar 222,2413793<APCU Awal<=440,5 dan
APCU Akhir $<=496,4901837$, target energi adalah 390 yaitu batas minimal adalah Energy > 337, tidak ada pelanggaran, dan Rate > 0,859628. Pada Reward Rule tersebut terdapat poin Rate yang tidak dapat dijelaskan darimana didapatkan nilai variabelnya. Rate sangat penting dalam penentuan komisi dimana jika para Game Streamer tidak memenuhi nilai Rate, walaupun semua persyaratan telah terpenuhi, mereka tetap tidak mendapatkan komisi. Sehingga perlu ada kriteria yang spesifik untuk mendapatkan bobot-bobot ideal yang harus dicapai oleh para pemain.

Oleh karena itu, perlu dilakukan studi lebih dalam untuk mengetahui fakta dengan memahami hubungan bisnis dan strateginya agar aturan komisi lebih transparan, sehingga tidak ada terdapatnya penyelewengan. Terlebih lagi dikarenakan bisnis ini termasuk tergolong baru di Indonesia, maka belum ada regulasi yang tepat dari pemerintah.

Selain itu, khusus pengolahan data pada Orange Data Mining perlu dikaji untuk membangun Regression Tree, dikarenakan bahwa beberapa data ternyata memiliki sifat numerik atau kontinu. Dengan kata lain, dimana tidak dapat diklasifikasi dengan cara pengelompokkan data, melainkan dalam pembangunan Decision Tree menggunakan rate error dari setiap pemisahan cabang. Oleh karena itu, dalam studi kasus ini diperlukan penelitian lanjutan.

\section{DAFTAR PUSTAKA}

[1] L. Sunarmintyastuti, D. Katarina, E. W. Ambarsari, and D. Fathudin, "KRITERIA NILAI PRODUK GAME EDUKASI MAHASISWA UNIVERSITAS DARMA PERSADA DENGAN METODE MAGIQ," 2019.

[2] A. Aditya, "Jokowi Buka Kompetisi Game Online Terbesar di ASEAN," 
CNBC Indonesia, 2018. [Online].

Available:

https://www.cnbcindonesia.com/ne

ws/20181017090302-4-

37699/jokowi-buka-kompetisi-

game-online-terbesar-di-asean.

[Accessed: 02-Apr-2019].

[3] J. Demšar et al., "Orange: Data Mining Toolbox in Python," $J$. Mach. Learn. Res., vol. 14, pp. 2349-2353, 2013.

[4] L. A. Hermanto, "Prakiraan Tinggi Gelombang Air Laut Menggunakan Data Mining," J. IPTEK, vol. 22, no. 1, p. 37, May 2018.

[5] P. Meilina, "Penerapan Data Mining Dengan Metode Klasifikasi Menggunakan Decision Tree dan Regresi," J. Teknol., vol. 7, no. 1, pp. 11-20, 2015.

[6] M. Stajdohar and J. Demsar, "Interactive Network Exploration with Orange," J. Stat. Softw., vol. 53, no. 6, pp. 1-24, 2013.

[7] E. Windia Ambarsari, "Klasifikasi Daya Tarik Konten Artikel Media Daring Dari Data Google Analytics Dengan C-FDT," J. Inform. $J$. Pengemb. IT, vol. 03, no. 02, pp. 211-218, 2018.

[8] I. Oktanisa and A. A. Supianto, "Perbandingan Teknik Klasifikasi Dalam Data Mining Untuk Bank Direct Marketing," J. Teknol. Inf. dan Ilmu Komput., vol. 5, no. 5, p. 567, Oct. 2018.

[9] D. Parwatiningtyas and E. W. Ambarsari, "CALCULATION ANALYSIS TO DETERMINE THE LARGEST EARTHQUAKE AREA AT NORTH SUMATERA USING J48 DECISION TREE METHOD," in The Proceeding of Ocean, Mechanical and Aerospace -Science and Engineering-(POMase), 2016, vol. 3 , no. 1 , pp. $36-43$.

[10] S. M. S. Askari and M. A. Hussain, "Credit card fraud detection using fuzzy ID3," in 2017 International Conference on Computing, Communication and Automation (ICCCA), 2017, pp. 446-452.

[11] W. Dai and W. Ji, "A mapreduce implementation of $\mathrm{C} 4.5$ decision tree algorithm," Int. J. Database Theory Appl., vol. 7, no. 1, pp. 4960, 2014.

[12] E. Ahishakiye, D. Taremwa, E. O. Omulo, and I. Niyonzima, "Crime Prediction Using Decision Tree (J48) Classification Algorithm," Int. J. Comput. Inf. Technol., vol. 06, no. 03, pp. 2279-764, 2017.

[13] T. Bujlow, T. Riaz, and J. M. Pedersen, "A method for classification of network traffic based on C5.0 machine learning algorithm," in 2012 International Conference on Computing, Networking and Communications, ICNC'12, 2012.

[14] H. Sharma and S. Kumar, "A Survey on Decision Tree Algorithms of Classification in Data Mining," Int. J. Sci. Res., vol. 5, no. 4, pp. 2094-2097, 2016.

[15] M. Friendly and D. Denis, "THE EARLY ORIGINS AND DEVELOPMENT OF THE SCATTERPLOT," J. Hist. Behav. Sci., vol. 41, no. 2, pp. 102-130, 2005.

[16] M. Budi, R. Karyadin, and S. Hartono Wijaya, "Perbandingan Algoritme Pruning pada Decision Tree yang Dikembangkan dengan Algoritme CART," 2010.

[17] N. Patel and S. Upadhyay, "Study of Various Decision Tree Pruning Methods with their Empirical Comparison in WEKA," Int. J. Comput. Appl., vol. 60, no. 12, pp. 20-25, Dec. 2012.

[18] S. J. J. Smith and D. S. Nau, "An Analysis of Forward Pruning," Aaai 1994, pp. 1386-1391, 1994. 